\section{ESCRITURAS DE LA AUSENCIA: LAS NOVELAS DE LOS HIJOS DE LAS POSDICTADURAS DE CHILE $Y$ ARGENTINA}

\author{
Macarena García-Avello \\ Universidad de Cantabria \\ ORCID iD: https://orcid.org/0000-0002-3390-8184 \\ gavellom@unican.es
}

\section{ABSENCE WRITING: THE CHILEAN AND ARGENTINE POST- DICTATORSHIP SONS' NOVELS}

Cómo citar este artículo/Citation: García-Avello, M. (2019). Escrituras de la ausencia: las novelas de los hijos de las posdictaduras de Chile y Argentina. Arbor, 195 (792): a521. https://doi.org/10.3989/arbor.2019.793n3009
Copyright: (C) 2019 CSIC. Este es un artículo de acceso abierto distribuido bajo los términos de la licencia de uso y distribución Creative Commons Reconocimiento 4.0 Internacional (CC BY 4.0).

Recibido: 5 febrero 2018. Aceptado: 6 enero 2019.

RESUMEN: Las reflexiones en torno a la escritura de acontecimientos traumáticos como fueron las dictaduras chilenas y argentinas genera una serie de aporías que podrían resumirse en las siguientes cuestiones: ¿cómo comprender aquello que sobrepasa toda comprensión?, ¿cómo narrar lo inenarrable?, ¿cómo recomponer los testimonios de acontecimientos desprovistos de testigos? En este ensayo me propongo explorar estos asuntos en relación con cuatro novelas que parten de la ausencia, en tanto el pasado de la dictadura -identificado no solo como irrepresentable, también como incomprensible- origina una falta o carencia de la que emerge la escritura. Concretamente se analizarán las novelas de los hijos, quienes eran aún niños durante la dictadura y por ello la vivieron de manera indirecta a través de sus padres: Formas de volver a casa (2011) de Alejandro Zambra, Una misma noche (2012) de Leopoldo Brizuela, El espíritu de mis padres sigue subiendo en la lluvia (2011) de Patricio Pron y Fuenzalida (2010) de Nona Fernández.

PALABRAS CLAVE: Segundas generaciones; ausencia; narración; posdictadura; literatura chilena; literatura argentina.
ABSTRACT: Reflections on the writings about traumatic events like the dictatorships in Chile and Argentina give rise to a number of aporias that can be summarised by the following questions: How can we understand events that exceed all possible comprehension? How can we narrate events that cannot be verbalised? How can we recollect the testimonies of events with no witnesses? Through this essay I aim to explore these issues in four novels that revolve around absence, as the past generates a lack or void from which writing emerges. More specifically, I will analyse the following novels of the children, those who were growing up during the dictatorships and only experienced it through their parents: Alejandro Zambra's Formas de volver a casa (2011), Leopoldo Brizuela's Una misma noche (2012), Patricio Pron's El espíritu de mis padres sigue subiendo en la lluvia (2011) and Nona Fernández's Fuenzalida (2010).

KEYWORDS: Second generations; absence; narration; postdictatorship; Chilean literature; Argentinean literature. 


\section{LA MEMORIA DE LAS SEGUNDAS GENERACIONES}

Las reflexiones en torno a la escritura de acontecimientos traumáticos como fueron las dictaduras chilena y argentina generan una serie de aporías que podrían resumirse en las siguientes cuestiones: ¿cómo comprender aquello que sobrepasa toda comprensión?, ¿cómo narrar lo inenarrable?, ¿cómo recomponer los testimonios de acontecimientos desprovistos de testigos? Según Luis Mateo Díez, "Ios novelistas se alimentan de la memoria, de la experiencia y de la imaginación, y por ahí fluimos hacia la palabra" (2001, p. 35). Pero ¿qué ocurre cuando la memoria se ve usurpada por la ausencia? En este ensayo propongo explorar estos asuntos en relación con dos novelas chilenas y argentinas que parten de la ausencia, en tanto el pasado de la dictadura -identificado no solo como irrepresentable, también como incomprensible- origina una falta o carencia de la que emerge la escritura. Concretamente se analizarán las novelas de los hijos, quienes eran aún niños durante la dictadura y por ello la vivieron de manera indirecta a través de sus padres: Formas de volver a casa (2011) del chileno Alejandro Zambra, Una misma noche (2012) del escritor argentino Leopoldo Brizuela, El espíritu de mis padres sigue subiendo en la lluvia (2011) del también argentino Patricio Pron y Fuenzalida (2010) de la autora chilena Nona Fernández. La problematización de la inscripción del pasado en estas obras comparte ciertos presupuestos con lo que Friederike Eigler ha denominado memory text. De acuerdo con la siguiente definición, esta clase de literatura "often comment on the processes of memory and the ways memory is rooted in the power of imagination and interpretation. To the extent they reflect on the processes of reconstructing and making sense of the past" (Eigler, 2001, p. 392). Los textos analizados, sin embargo, giran en torno a la brecha que se abre ante un pasado que parece haber sido amputado, dejando un vacío cuyos contornos se van iluminando a través de la escritura.

La cuestión central que planteo es: ¿qué puede aportar esta ficción que, tal como se mostrará a continuación, se erige sobre la ausencia? Con el propósito de dar respuesta a esto comenzaré con un repaso de las distintas circunstancias que motivan la ausencia en cada una de las novelas, para proceder a continuación con un análisis sobre cómo se articulan estas narrativas. De este modo pretendo demostrar que la elaboración de la ausencia constituye un acto, en ocasiones incluso una necesidad ética. Para los autores estudiados, la escritura no se limita a denunicar, a informar ni a desempeñar una función política en el sentido estricto de la palabra, sino que se convierte en un medio para preservar la memoria de un vacío o pérdida de la cual se sienten herederos. El papel de los narradores se corresponde con el deber moral que Ricoeur atribuye al novelista cuando se pregunta: "Deuda por deuda, ¿quién es más insolvente, el historiador o el novelista?" (1995, p. 917). A pesar de sus diferencias, todas estas obras se enfrentan a una disyuntiva entre la necesidad ética de rememorar y la problemática de la representación. De ahí que la metaficción, la auto-reflexividad y los límites entre realidad y ficción en la narración de historias atravesadas por el trauma constituyan componentes centrales que deberán analizarse con el fin de determinar la manera en que cada una propone lidiar con la herencia que representa un pasado que solo se conoce de manera indirecta.

\section{ELABORACIONES DE LA AUSENCIA}

La ausencia es un componente central en "las novelas de los hijos", las segundas generaciones que, a pesar de arrastrar unas secuelas, no vivieron la traumática experiencia de sus padres, o si lo hicieron fue de manera indirecta, sin llegar a entender el alcance de lo ocurrido. Su experiencia puede entenderse en relación con el concepto de la posmemoria que Marianne Hirsch (2008) formula en respuesta a los síntomas postraumáticos padecidos por las segundas generaciones de supervivientes del Holocausto. La posmemoria rompe con el principio según el cual la memoria ha de ir necesariamente precedida por la experiencia. Esta falta de correlación o ausencia ha puesto de manifiesto la necesidad de instaurar una nueva categoría de análisis. Hirsch se centra en el análisis de las segundas generaciones que manifiestan síntomas propios del trastorno postraumático, con la diferencia fundamental de que el trauma no forma parte de sus vivencias personales, sino que se ha transmitido por vías indirectas de una generación a la otra. En las novelas de los hijos se produce un desdoble entre dos tiempos, el pasado recreado de la dictadura y el presente del narrador desde el que se trata de recuperar el pasado, ya sea por medio de la imaginación, de huellas de la memoria o, en la mayor parte de los casos, mediante recuerdos diluidos y atravesados por la imaginación.

Formas de volver a casa se abre y cierra con dos terremotos distintos, comienza con el de 1985 en plena dictadura chilena, y finalmente acaba con el de 2010, proporcionando así a la novela una estructura circular en la que dos temporalidades, el pasado de la dictadura y el presente de la posdictadura, se intercalan constantemente. Las secciones Personajes secundarios y La literatura de los hijos trazan la historia de un niño de nueve años que se dedica a espiar a su vecino por orden de una compañera algo mayor, Claudia, a quien conoce el día del primer terremoto. Años después descubre que el hombre al que vigilaba era el padre de Claudia, oculto por su vinculación con el comunismo. Paralelamente los capítulos La literatura de los padres y Estamos bien se centran en las reflexiones del adulto, cuyos esfuerzos por escribir su novela se ven frustrados ante una serie de lagunas e interrogan- 
tes sin aparente respuesta. La vuelta al hogar implica revisitar un pasado que plantea diversas incógnitas, y que al escaparse del conocimiento y experiencias personales del narrador no se elabora a través de la memoria, sino de la ficción. Asimismo, se trata de un retorno motivado por el deseo de interrogar a los padres, de exigirles responsabilidades que finalmente se tornarán sobre él mismo. La manera en la que el narrador vuelve compulsivamente sobre el pasado para intentar redimirlo por medio de la narración parece ratificar las palabras de Ricoeur: "hay crímenes que no deben olvidarse, víctimas cuyo sufrimiento pide menos venganza que narración. Solo la voluntad de no olvidar puede hacer que estos crímenes no vuelvan nunca más" (1995, p. 912).

A través de los reproches a estos padres caracterizados como apolíticos se señala la imposibilidad de hallar inocentes, pues todos de una manera u otra han estado involucrados en lo sucedido. Dentro de este marco, la literatura sirve para denunciar lo que desde la política de estado se trató durante años de silenciar. Con respecto a esto, Nelly Richard indica que "de todo el repertorio simbólico de la historia chilena reciente, la figura de la memoria ha sido la más fuertemente dramatizada por la tensión irresuelta entre recuerdo y olvido, y también, entre latencia y muerte, revelación y ocultamiento, prueba y denegación, sustracción y restitución" (1994, p. 109). Si bien esto no se da exclusivamente en el contexto chileno, sí es cierto que en este país adquiere unas connotaciones específicas debido al hecho de que en Chile la transición democrática fue el producto de un pacto entre las élites políticas y los altos cargos militares que habían actuado como "the very architects of the repression" (Ros, 2012 , p. 4). La literatura, por tanto, asume en muchos casos un papel central a la hora de poner el foco sobre ciertos silencios impuestos desde el ámbito político y jurídico.

De ahí el papel de la ficción de reelaborar el pasado desde un presente que le otorgue una función política. Esto es, en última instancia, lo que se encarga de hacer el narrador al rescatar un recuerdo que solo visto a la luz del presente obtiene una lectura política. En la siguiente cita se incide en cómo esta reelaboración del pasado con los ojos del presente proporciona al relato ciertos efectos redentores: "Pinochet, para mí era un personaje de la televisión que conducía un programa sin horario fijo, y lo odiaba por eso, por las aburridas cadenas nacionales que interrumpían la programación en las mejores partes. Tiempo después lo odié por hijo de puta, por asesino, pero entonces lo odiaba solamente por esos intempestivos shows que mi papá miraba sin decir palabra" (Zambra, 2011, p. 21). Aunque el padre sea el espectador silencioso, este se describe a través de la mirada del hijo que observa el pasado desde el prisma otorgado por el presente; es decir, lo reevalúa mediante la incorporación del conocimiento contextual del que carecía en aquella época.

Una misma noche comienza con el asalto a unos vecinos en el año 2010 que aflora en el narrador el recuerdo reprimido de su padre veinticuatro años atrás derribando la misma puerta para dejar pasar a la policía en la casa de los Kuperman, la familia que por aquel entonces vivía allí. A través de las cuatro secciones Novela, Memoria, Historia y Sueño, se busca rescatar el pasado traumático asociado con la dictadura argentina desde la mirada del adulto que asume el papel del testigo. La narración es el canal mediante el que se trata de superar la barrera entre el yo y el otro, el presente y el pasado o, en palabras del propio autor, "la escritura es una manera única de iluminar la conexión entre el pasado y el presente. Y eso me alienta a empezar: no como quien informa, sino como quien descubre" (Brizuela, 2012, p. 43). En este caso el pasado traumático que se recrea obsesivamente en el presente remite, por una parte, a la detención de Diana Kuperman y, por otra, a la imagen de su padre tirando abajo la puerta. Se establece así una identificación patológica entre el testigo y la víctima que le lleva a desarrollar una serie de síntomas postraumáticos. La problemática que implica la representación del trauma se refleja en esta obra mediante técnicas estilísticas como la fragmentación, la ruptura de la linearidad, la falta de teleologismo o la dilación. De este modo la trama se intercala con una serie de reflexiones metaficcionales en torno al papel de la escritura: Tal como se encarga de advertir el narrador: "Quizá mis rejas sean la escritura. Pero quizá las cosas se repiten para que uno comprenda, me digo, y mi modo de entender es escribir" (Brizuela, 2012, p. 60).

En El espíritu de mis padres sigue subiendo en la Iluvia, el narrador, residente en Alemania, regresa a Argentina tras habérsele notificado la enfermedad terminal de su padre. Este retorno le lleva a indagar en el pasado paterno, tratando de reconstruir su experiencia de la dictadura a través de los recortes de prensa que su padre guardaba. Las noticias giran en torno al asesinato de un hombre para robarle la indemnización que había adquirido unos años antes por la desaparición de su hermana durante la dictadura. Este descubrimiento abre un doble enigma: el del asesinato y el del por qué esta historia llamó la atención de su padre.

Un día, supongo, en algún momento, los hijos tienen necesidad de saber quiénes fueron sus padres y se lanzan a averiguarlo. Los hijos son los detectives de los padres, que los arrojan al mundo para que un día regresen a ellos para contarles su historia y, de esa manera, puedan comprenderla. No son sus jueces, puesto que no pueden juzgar realmente con imparcialidad [...] pero pueden intentar poner or- 
den en su historia, restituir el sentido que los acontecimientos más o menos pueriles de la vida y su acumulación parecen haberle arrebatado, y luego proteger esa historia y perpetuarla en la memoria (Pron, 2011, pp. 12-13).

La búsqueda se retoma en Fuenzalida, cuando la protagonista encuentra una fotografía de un hombre que cree que podría ser su padre. La fotografía conecta a través de la imaginación las dos temporalidades sobre las que se construye una trama que cuenta, por una parte, la historia de una narradora que no sabe cómo responderle a su hijo la pregunta de quién fue su abuelo y, por otro lado, la historia imaginaria de su padre, Ernesto Fuenzalida, transcurrida durante la dictadura. Esta narración en torno a lo posible surge para hacer frente al vacío que rodea la figura paterna: "Mi memoria estaba en blanco, como un rollo fotográfico vedado, no arrojaba ninguna imagen. La verdad es que no arrojaba nada de nada, así que nada respondí. No había historia, no había relato" (2010, p. 37). El deseo del hijo de conocer la identidad de su abuelo remite a la famosa constatación de Ricoeur de que a la pregunta del quién siempre ha de responderse mediante una narrativa. En Sí mismo como otro, Ricoeur observa que de la pregunta quién se derivan "todas las aserciones relativas a la problematica del sí [...]. Cuatro subconjuntos corresponden así a cuatro maneras de interrogar: ¿quién habla?, ¿quién actúa?, ¿quién se narra?, ¿quién es el sujeto moral de imputación?" (2006, p. xix). Sin embargo, Ernesto Fuenzalida es un significante vacío de significado, ya que la narradora solo cuenta con piezas sueltas de un pasado del que apenas sabe nada. No obstante, el reconocimiento de la historia de su padre como una hoja en blanco le permite disponer libremente de pedazos de su infancia para unirlos a episodios imaginados de un karateca que accidentalmente se ve presionado a cooperar con los agentes de la dictadura. La negativa de Fuenzalidad a colaborar con el régimen lleva a uno de los líderes del grupo represor, el sanguinario Raúl Fuentes Castro, a secuestrar a su hijo. Para poder recuperar a su hijo, Fuenzalida debe enfrentarse a Raúl en un combate de artes marciales cuyo desenlace se desconoce.

De este primer acercamiento a las obras se desprende una visión de la ausencia como el punto de partida sobre el que se van construyendo y estructurando las novelas. Dicha ausencia o vacío tiene su origen en el pasado de una dictadura que se manifiesta como huella remanente de un trauma que no ha sido aprehendido ni comprendido. Esto se asemeja a la manera en que, según Cathy Caruth, el trauma no se comprende en el momento, sino posteriormente por medio de una serie de síntomas: "the event is not assimilated or experienced fully at the time, but only belatedly, in its repeated possession of the one who experiences it. To be traumatized is precisely to be possessed by an image or event" (1995, pp. 4-5). Las novelas analizadas evidencian cómo la violencia inherente al trauma de la dictadura promueve una disociación inicial que suele ir acompañada de la oscilación entre la represión inicial y una repetición que ilustra la observación de Assman de que "[t]hose who cannot remember their past are condemned to relive it" (2008, p. 110).

Basándose en el ensayo Duelo y melancolía (1917) de Freud, el historiador Dominick LaCapra identifica dos posibles respuestas al trauma, acting-out y working-through, traducidas respectivamente como pasaje al acto y elaboración del duelo. Durante la fase del pasaje al acto, la víctima, tal como describe LaCapra, experimenta "compulsive repetition, is possessed by the past, faces a future of impasses, and remains narcissistically identified with the lost object" (1999, p. 713). En The Archetypes and the Collective Unconscious (1959), Carl Jung formula la tesis, convertida en uno de los pilares del psicoanálisis, de que la recuperación psicológica tras el trauma es posible por medio de la expresión verbal del sufrimiento. LaCapra se hace eco de la necesidad de dar salida al trauma a través del lenguaje, de ahí que la elaboración del duelo reclame una narrativa como la que ofrecen las novelas aquí incluidas. En todas ellas aparece la repetición como elemento constitutivo que funciona como respuesta a un pasado traumático desconocido que se trata de elaborar por medio de la narración. En palabras de Paul Valéry, "[o]ur memory repeats to us what we haven't understood. Repetition is addressed to incomprehension" (Felman y Laub, 1992, p. 144). Puesto que el reconocimiento del acontecimiento traumático es una condición necesaria para la elaboración del pasado, la pregunta que emerge es: ¿cómo narrar aquellos recuerdos que al no estar precedidos por la experiencia parecen encontrarse absorbidos por la ausencia?

\section{LA NARRACIÓN DEL PASADO}

La narración de un pasado que no se ha vivido y del que solo se tiene conocimiento por medio de los testimonios de otros atraviesa las novelas de las segundas generaciones. Cada una de las cuatro obras seleccionadas ofrece un acercamiento distinto al tema de la memoria de segunda mano. En la introducción se adelantó el término de Marianne Hirsch de la posmemoria para referirse a la experiencia narrada por estos autores: "a response of the second generation to the trauma of the first" (2001, p. 8). Según explica Hirsch (2008), el "pos" señala un desplazamiento con respecto al espacio y tiempo del recuerdo original, pero lejos de representar un corte, la partícula denota continuidad, indicando un encadenamiento entre la memoria y la posmemoria. El trabajo pionero de Maurice Halbwachs también tiene en cuenta esta 
dimensión de la memoria, pues si bien Halbwachs rechaza que el conocimiento de acontecimientos ajenos a la experiencia del sujeto pueda llamarse memoria, cuando no existe una experiencia previa a lo evocado introduce el concepto de borrowed memory para aludir a los recuerdos de otros: "I can imagine them, but I cannot remember them" (1980, p. 51).

En El espíritu de mis padres sigue subiendo en la lluvia se observa cómo el vínculo emocional del sujeto con los eventos en cuestión opone la posmemoria a la concepción desapasionada y pretendidamente imparcial de la historia: "mi padre siempre había tenido una mala memoria. Él decía que la tenía como un colador, y me auguraba que yo también la tendría así porque, decía, la memoria se lleva en la sangre" (Pron, 2011, p. 21). A través del narrador se plantea la posibilidad de padecer las secuelas de un pasado que nunca se experimentó, lo que traza interesantes lazos entre el presente del sujeto y el pasado paterno. Los obstáculos a la hora de reconducir la melancolía hacia el trabajo del duelo se multiplican al tratarse de un trauma heredado, pues el legado de la posmemoria consiste en una "memoria vicaria". En su ensayo Tiempo pasado: cultura de la memoria y giro subjetivo (2005), Beatriz Sarlo considera que la naturaleza vicaria y fragmentaria de la posmemoria es extrapolable a la memoria. No obstante, lo que según la autora diferencia a la posmemoria es el grado de implicación que supone para el hijo: "Sólo la memoria del padre; si el discurso que provoca en el hijo quiere ser llamado posmemoria, lo será por la trama biográfica y moral de la transmisión, por la dimensión subjetiva y moral. No es en principio necesariamente ni más o menos fragmentaria, ni más ni menos vicaria, ni más ni menos mediada que la reconstrucción realizada por un tercero; pero se diferencia de ella porque está atravesada por el interés subjetivo vivido en términos personales (2005, p. 131)

En Una misma noche, el narrador parece heredar el trauma de Diana Kuperman, en cuyo arresto colaboró muy colateralmente su padre. El narrador rememora obsesivamente la escena de esa noche hasta llegar a establecer una identificación con la víctima que le lleva a imaginar cuatro variaciones en torno a su arresto. Tanto el pasado del padre de Pron como el de Diana están inmersos en un "agujero negro", o lo que Raczymow y Astro definen como la mémoire trouée (1994). Ambas historias no solo sobrepasan la experiencia de los narradores, sino también su conocimiento. Como consecuencia de ello, sus vidas están marcadas por un pasado que, además de no pertenecerles, se compone del silencio patológico que constituye el principal legado de sus padres. En este contexto, es muy sugerente la comparación que Fresco establece con la amputación de un órgano: "The amputated are left only with phantom pains, but who can say that the pain left in a hand that one no longer has is not pain" (1984, p. 420). La transmisión de esta herida sin memoria crea una ausencia avivada por el silencio que envuelve el pasado paterno y el de Diana. El sentimiento comparable a la amputación de un órgano que nunca fue suyo ocasiona "a phantom pain in which amnesia takes the place of memory [...] One remembers only that one remembers nothing" (Fresco, 1984, p. 421). En la novela de los hijos, el vacío o falta de recuerdos impulsa a volver compulsivamente sobre el pasado con el fin de reconstruirlo. Sin embargo, los intentos están abocados al fracaso debido a las lagunas inherentes a una memoria prestada. Puesto que no existe un órgano previo a la amputación, la ausencia se erige como componente consustancial de la identidad.

La mémoire trouée se encuentra estrechamente vinculada a la fragmentación del yo, cuya sensación de desintegración se debe a que el sujeto se ve despojado de un pasado que paradójicamente no pertenece a su experiencia vital. "To grow up with such overwhelming inherited memories, to be dominated by narratives that preceded one's birth or one's consciousness, is to risk having one's stories and experiences displaced, even evacuated, by those of a previous generation" (Hirsch, 2012, p. 107). La identificación patológica del narrador se entremezcla con un sentimiento de culpabilidad agravado por el desconocimiento de la historia del padre y de Diana. A través de ambas novelas se trata de redimir las lagunas del pasado ajeno por medio de la imaginación y la escritura de ficción. De este modo, la narración se proyecta como una búsqueda que desempeña una función ética, tal como señala el siguiente fragmento de El espíritu de mis padres sigue subiendo en la lluvia:

Al procurar dejar atrás las fotografías que acababa de ver comprendí por primera vez que todos los hijos de los jóvenes de la década de 1970 íbamos a tener que dilucidar el pasado de nuestros padres como si fuéramos detectives y que lo que averiguaríamos se iba a parecer demasiado a una novela policial que no quisiéramos haber comprado nunca, pero también me di cuenta de que no había forma de contar su historia [...] o, mejor aún, que hacerlo de esa forma sería traicionar sus intenciones y sus luchas (Pron, 2011, p. 170).

Formas de volver a casa presenta una situación muy distinta, pues los padres no son ni víctimas ni victimarios, sino personas que aparentemente se mantuvieron al margen de la política. A través de la novela se problematiza tanto la actitud y responsabilidad de estos testigos "neutrales" como la de sus hijos. La historia comienza con un niño desorientado que se afana en encontrar el camino de vuelta a casa solo para descubrir que son sus padres quienes 
se han perdido. Este retorno, por lo tanto, cuestiona la actitud paterna hacia el pasado y su incapacidad presente de enfrentarse al mismo: "Voy a escribir un libro sobre ustedes, les digo, con una sonrisa extraña dibujada en la boca. No puedo creer lo que acaba de ocurrir. Me molesta ser el hijo que vuelve a recriminar, una y otra vez, a sus padres. Pero no puedo evitarlo" (Zambra, 2011, p. 131).

No obstante, tanto la narración de la novela de los padres como la historia de Claudia funcionan como una especie de espejo que refleja al narrador en su presente. "Entonces recordé intensamente a Claudia, pero no quería o no me atrevía a contar su historia. No era mía. Sabía poco, pero al menos sabía eso: que nadie habla por los demás. Que aunque queramos contar historias ajenas terminamos siempre contando la historia propia" (Zambra, 2011, p. 105). El presente sirve al narrador para saldar una deuda con el pasado. Aunque el niño desconociera en esos momentos lo que estaba ocurriendo, el adulto tiene la responsabilidad de volver sobre ese pasado y reelaborarlo con el fin de otorgarle una visión política que en aquel momento estaba ausente. El peso de la memoria genera un sentimiento de responsabilidad que, en vez de tratar de mitigarse con el olvido, debe canalizarse hacia la búsqueda de una forma legítima de representar y rememorar las pérdidas. Como Whitehead explica, "[t]he weight of memory may embroil us but it also connects us both to others and to reality itself [...] remembering seems to assume a crucial moral and ethical dimension [...] it is also a responsibility" (2009, pp. 87-88). La ficción analizada avala la convicción de que el olvido, además de inviable, supondría una especie de traición. La supervivencia confiere a los narradores el papel de guardianes del recuerdo, cuyo deber hacia el pasado se materializa a través de la escritura.

La novela es la novela de los padres, pensé entonces, pienso ahora. Crecimos creyendo eso, que la novela era de los padres. Maldiciéndolos y también refugiándonos, aliviados, en esa penumbra. Mientras los adultos mataban o eran muertos, nosotros hacíamos dibujos en un rincón. Mientras el país se caía a pedazos nosotros aprendíamos a hablar, a caminar, a doblar las servilletas en forma de barcos, de aviones. Mientras la novela sucedía, nosotros jugábamos a escondernos, a desaparecer (Zambra, 2011, p. 57).

La búsqueda recogida en Fuenzalida abarca la representación de los recuerdos de la narradora y la ficción que crea como respuesta al vacío que envuelve la historia del padre. Puesto que el pasado paterno se reduce a un agujero negro, la narración no se apoya en la memoria, sino fundamentalmente en la imaginación: "Mis escasos momentos con él tienen la forma de una fotografía cortada con una tijera. No hay mucho de qué hablar. Una historia sin desarrollo, sin final. Sólo el punto de partida, los primeros diez capítulos del culebrón. Fuenzalida desapareció. Se borró del mapa" (2010, p. 42). El padre representa el silencio, es el hueco que ha sido arrancado en las fotos familiares: "hoyos negros tijereteados. Espacios en blanco, interrogantes" (2010, p. 35). Tal como se explica con mayor detalle en el artículo "Inventa un cuento que te sirva de memoria: Narración del Vacío de Fuenzalida de Nona Fernández" (2016), las fotografías pueden analizarse como archivos cuya función es la de dejar al descubierto la violencia, la supresión y la represión, motivando la creación de la narrativa que lleva a cabo la protagonista. El hecho de que el espacio ocupado por el padre haya sido eliminado de forma tan brutal hace imposible obviar los silencios que rodean la narrativa de la infancia. Las fotos exhiben el recorte, lo que hasta entonces se ha reprimido invade la imagen, empañando el espacio mediante un ineludible agujero negro. Los interrogantes a los que la narradora alude marcan una incertidumbre que se proyecta hacia la búsqueda de posibles respuestas (García-Avello, 2016, p. 264).

Las fotografías ocupan un lugar central en las narrativas que giran sobre el pasado de la dictadura; según Ornella Lepri Mazzuca, "visual images acquire a privileged role between the political and historical circles. At this point, politics and history cannot escape from the memory frame and the audiovisual cultural frame" (2005, p. 132). Si bien la fotografía aparece como uno de los temas recurrentes en las novelas de los hijos, su función en estos casos no es la de verificar, pues los narradores se encuentran ante imágenes que, al carecer de contexto, carecen también de significado. Paradójicamente, el hecho de liberar estas fotografías de un referente en el pasado permite a los narradores dar rienda suelta a su imaginación. Las fotografías se utilizan como punto de partida sobre el que recrear e imaginar episodios y situaciones en torno a imágenes sin contento: "What makes photography a strange invention -with unforseeable consequences- is that its primary raw materials are light and time" (Berger, 1995, p. 97). Las narraciones de las segundas generaciones explotan la potencialidad de la fotografía mediante el sometimiento de las imágenes a una multiplicidad de interpretaciones, lo que a su vez demuestra una dualidad entre su naturaleza referencial y su carácter construido. Aunque la fotografía se considere un hecho objetivo, las obras analizadas evidencian cómo la interpretación o lectura es necesariamente subjetiva. Carente de contexto, los hijos se encargan de inventárselo, de modo que las fotografías dejan de identificarse como una vía de acceso transparente o directa al pasado para mostrarse como representaciones construidas y mediadas por el lenguaje. Esto pone de manifiesto cómo el pasado que los narradores tratan de rescatar narrativamente es una construcción. 
La indeterminación que atraviesa los textos impide que se caiga en la falsa impresión de que el pasado es susceptible de ser recuperado. La única certeza que parece firme es la existencia de una proliferación de significantes orientados a deconstruir significados trascendentales y narrativas totalizadoras. El resultado es un vacío o silencio, cuya negatividad se afirma mediante una renarración, no de lo factual, sino en torno a lo posible. Una imagen muy sugerente que señala el potencial de elaborar pasados alternativos a través de la imaginación se muestra en el siguiente fragmento en el que Fuenzalida lucha contra su propio reflejo en una sala llena de espejos: "Ernesto Fuenzalida entra a un salón de combate hecho de espejos. Un lugar donde cada una de las paredes de vidrio le devuelve su imagen reflejada al infinito. Muchos Ernestos Fuenzalida, muchas posibilidades, muchas versiones de sí mismo" (2010, p. 244).

\section{CONCLUSIÓN}

El reconocimiento de la ausencia permite dar rienda suelta a la imaginación, empleada a lo largo de las novelas como instrumento con el que especular sobre las alternativas irrealizadas que esconde el pasado. De acuerdo con Ricoeur, "una de las funciones de la ficción, unida a la historia, es la de liberar retrospectivamente ciertas posibilidades no efectuadas del pasado histórico [...] El cuasi pasado de la ficción se convierte así en el revelador de los posibles escondidos en el pasado efectivo" (1995, p. 916). La narración está motivada por imperativos éticos que en las cuatro novelas analizadas van ligados al reconocimiento de la problemática que suscita toda representación del pasado.

Las obras estudiadas ofrecen una alternativa ante los silencios que inundan un pasado que, a pesar de parecer en primera instancia impenetrable, es susceptible de ser reelaborado mediante la imaginación. Los silencios y "agujeros negros" articulan una ausencia que reclama ser escuchada y que en efecto adquiere materialidad por medio de la escritura. La visión del pasado subyacente a las novelas de los hijos es comparable a la caracterización del escritor francés Henri Raczymow de su propia ficción como la huella de la pérdida: "It is the proof or the mark of the loss -its trace. So a trace remains. In turn, we can lose the trace. Lose the loss itself. Lose, if you will, the feeling of loss. And dissolve into nothing" (1994, p. 100). Según esta visión, la narrativa funciona como el testimonio de una ausencia que remite a un pasado irrecuperable, pero no inimaginable. De esto se desprende una revalorización de la fantasía que si bien en ningún caso se equipara con la memoria, sí contribuye a llenar de posibilidades el silencio.

\section{BIBLIOGRAFÍA}

Assmann, J. (2008). Communicative and Cultural Memory. En: Astrid E. y Nünning, A. (eds). Cultural Memory Studies: An International and Interdisciplinary Handbook Berlin: Walter de Gruyter, pp. 110-120.

Berger, J. (1995). Another Way of Telling. New York: Vintage.

Brizuela, L. (2012). Una misma noche. Madrid: Alfaguara.

Caruth, C. (1995). Trauma Explorations in Memory. Baltimore: The John Hopkins University Press.

Eigler, F. (2001). Engendering Cultural Memory in Selected Post-Wende Literary Texts of the 1990s. The German Quarterly, 74 (4), pp. 392-406. https://doi. org/10.2307/3072633

Felman S. y Laub, D. (1992). Testimony. Crises of Witnessing in Literature, Psychoanalysis, and History. New York: Routledge.

Fernández, N. (2010). Fuenzalida. Barcelona: Mondadori.
Fresco, N. (1984). Remembering the Unknown. International Review of PsychoAnalysis, 11 (4), pp. 417-427.

García-Avello, M. (2016). “Inventa un cuento que te sirva de memoria": Narración del vacío en Fuenzalida de Nona Fernández. Chasqui Arizona State University XXXV, pp. 249-260.

Halbwachs, M. (1980). The Collective Memory. New York: Harper and Row.

Hirsch, M. (2001). Surviving Images: Holocaust Photographs and the Work of Postmemory. The Yale Journal of Criticism, 14 (1), pp. 5-37. https://doi. org/10.1353/yale.2001.0008

Hirsch, M. (2008). The Generation of Postmemory. Poetics Today, 29 (1), pp. 103-128. https://doi. org/10.1215/03335372-2007-019

Hirsch, M. (2012). The Generation of Postmemory. New York: Columbia University Press.

LaCapra, D. (1999). Trauma, Absence, Loss. Critical Inquiry 25 (4), pp. 696-727.
Lepri Mazzuca, O. (2005). Alternative Pasts in Post-Pinochet Chile: The Relation of History, Fiction and the Subjetification of History. En: Nagy-Zekmi, S. y Leiva, F. (eds.). Democracy in Chile. The Legacy of September, 11, 1973. Brighton: Sussex Academic Press, pp. 130-145.

Mateo Díez, L. (2001). La mano del sueño. (Algunas consideraciones sobre el arte narrativo, la imaginación y la memoria). Madrid: Real Academia Española.

Pron, P. (2011). El espíritu de mis padres sigue subiendo en la lluvia. Random House.

Raczymow, H. y Astro, A. (1994). Memory Shot Through with Holes. Yale French Studies, 85, pp. 98-105. https://doi. org/10.2307/2930067

Richard, N. (1994). La insubordinación de los signos. (Cambio político transformaciones culturales y poéticas de la crisis). Santiago: Cuarto Propio.

Ricoeur, P. (1995). Tiempo y narración. Buenos Aires: Siglo XXI.

Ricoeur, P. (2006) Sí mismo como otro. Madrid: Siglo XXI. 
Ros, A. (2012). The Post-Dictatorship Generation in Argentina, Chile and Uruguay. New York: Palgrave Macmilan. https:// doi.org/10.1057/9781137039781
Sarlo, B. (2005). Tiempo pasado: cultura de la memoria y giro subjetivo. Buenos Aires: Siglo XXI.
Whitehead, A. (2009). Memory: The New Critical Idiom. New York: Routledge.

Zambra, A. (2011). Formas de volver a casa. Barcelona: Anagrama. 